\title{
Original
}

\section{La tomografia por emisión de positrones (PET) y PET-TAC en riñón, vias urinarias y próstata: Actualización}

\author{
Roberto C. Delgado Bolton*,**, Jorge Mucientes Rasilla*, Ma Jesús Pérez Castejón**, \\ José L. Carreras Delgado*
}

*Servicio de Medicina Nuclear, Hospital Clínico San Carlos. Madrid.

**Instituto PET Focuscan. Madrid.

\begin{abstract}
Resumen
La PET ha demostrado su utilidad en la toma de decisiones diagnóstico-terapéuticas en diversos tipos de tumores. En los tumores del tracto urinario y del cáncer de próstata su rendimiento diagnóstico ha sido menor debido a la eliminación urinaria del radiotrazador que puede enmascarar la presencia de lesiones. No obstante, deben aplicarse protocolos específicos que mejoran el rendimiento diagnóstico de la PET con ${ }^{18} \mathrm{~F}$-FDG en la valoración de lesiones pélvicas. Además, el cáncer de próstata es un tumor de bajo grado con escasa avidez por la ${ }^{18} \mathrm{~F}$-FDG. A pesar de estas limitaciones, con la PET se han planteado nuevas e interesantes posibilidades diagnósticas. La disponibilidad de equipos PET-TAC ha mejorado su rendimiento diagnóstico. Por otra parte, el desarrollo de nuevos radiotrazadores que permiten marcar otros procesos moleculares y que son metabolizados por vías diferentes de la urinaria, supone una ventaja importante respecto a la ${ }^{18} \mathrm{~F}$-FDG $\mathrm{y}$ han proporcionado resultados interesantes.
\end{abstract}

Palabras clave: FDG- colina. Acetato. PET. PET-TAC. Vejiga. Próstata. Renal. Cancer urológico.

\section{Positron emission tomography (PET) and PET-CT in renal, bladder and prostate cancer: Update Abstract}

PET has demonstrated its utility in management decisions in several types of tumors. In urologic tract tumors and prostate cancer its diagnostic performance has been lower due to the urinary excretion of the radiotracer, which can mask the presence of lesions. However, specific protocols must be applied that improve the diagnostic performance of PET with ${ }^{18} \mathrm{~F}$ FDG in the evaluation of pelvic lesions. Furthermore, prostate cancer is a low-grade tumor with low avidity for ${ }^{18} \mathrm{~F}$-FDG. In spite of these limitations, with PET new and interesting possibilities have been presented. The availability of PET-CT systems has improved its diagnostic performance. On the other hand, the development of new radiotracers that allow targeting other molecular processes and that are metabolized by pathways different to the urinary tract signifies an important advantage compared to ${ }^{18} \mathrm{~F}-\mathrm{FDG}$ and has evidenced interesting results.

Keywords: FDG. Choline. Acetate. PET. PET-CT. Bladder. Prostate. Renal. Urologic cancer.

$\mathrm{L}^{2}$ a aplicación de la tomografía por emisión de positrones (PET) y PET-TAC con ${ }^{18} \mathrm{~F}$-fluorodeoxiglucosa ( $\left.{ }^{18} \mathrm{~F}-\mathrm{FDG}\right)$ en los tumores de riñón, vías urinarias y próstata ha sido limitada en comparación con otros tumores. Esto se ha debido fundamentalmente a la eliminación urinaria de la ${ }^{18}$ F-FDG, que frecuentemente impide una correcta visualización tanto del tumor primario como de la afectación linfática regional. Otro aspecto no menos relevante es la avidez por la ${ }^{18} \mathrm{~F}$-FDG de estos tumores. En cuanto a los tumores primarios y metastáticos de próstata, muestran reducidas tasas de metabolismo de glucosa y, por tanto, presentan escasa avidez por la ${ }^{18}$ F-FDG. Respecto a los carcinomas de células renales, muestran un comportamiento biológico más variable que el resto de los tumores. A continuación se analizan las ventajas y limitaciones de la PET y PET-TAC en los tumores renales, en los tumores de vejiga y en el cáncer de próstata.

\section{CARCINOMA DE CÉLULAS RENALES (CCR)}

El carcinoma de células renales (CCR) es el tumor renal sólido más frecuente. El planteamiento diagnóstico-terapéutico en tumores renales pequeños está en continuo cambio y en la actualidad los urólogos necesitan incorporar información nueva e importante en la planificación de la cirugía. El diagnóstico inicial de las masas renales habitualmente 
se realiza mediante ecografía, TAC o RM ${ }^{1,2}$. En la mayoría de los casos $(70 \%)$ son hallazgos casuales o incidentales durante exploraciones TAC por otros procesos $^{1,2}$. De estas masas, el 54\% corresponde al $\mathrm{CCR}$, que es potencialmente maligno y que raramente desarrolla su potencial metastásico con tamaños de $4 \mathrm{~cm}$ o menos ${ }^{2,3}$. Aunque todos los tumores renales (tanto los tumores benignos, como de bajo grado o malignos) pueden aumentar de tamaño con el tiempo, el potencial metastático es intrínseco al subtipo histológico. Alrededor del 90\% de los pacientes que desarrollan enfermedad metastásica presentan el subtipo histológico de $\mathrm{CCR}^{2,4}$.

Actualmente, el procedimiento de imagen de elección para valorar masas renales es la TAC ${ }^{5,6}$. La sensibilidad y especificidad de la TAC está por encima del 90\%7 . La TAC y la RM también aportan información importante sobre el tamaño, extensión del tumor, invasión vascular, todos ellos factores que son esenciales para la estadificación, pronóstico y planificación de la cirugía ${ }^{6}$.

En cuanto a la PET, aunque actualmente no es el procedimiento diagnóstico de elección, se han publicado estudios en los que se analiza su rendimiento diagnóstico en estos pacientes ${ }^{7,8}$.

Recientemente se ha publicado un meta-análisis sobre el rendimiento de la PET con ${ }^{18} \mathrm{~F}$-FDG en pacientes con CCR, que incluyó artículos publicados hasta octubre de $2004^{14}$. En este meta-análisis se incluyeron 7 estudios: tres de ellos se ocupaban del diagnóstico inicial $^{7,9,10}$, dos se referían a la reestadificación ${ }^{11,12}$, y dos de ellos se referían a la detección de metástasis ${ }^{8,13}$. Los tres estudios que analizaban el diagnóstico inicial $^{7,9,10}$ presentaron una sensibilidad conjunta de 0,67 (IC 95\%, 0,59-0,76) y una especificidad conjunta de 0,93 (IC 95\%, 0,86-0,97), aunque se detectó heterogeneidad tanto en la sensibilidad como en la especificidad, lo que dificultó la obtención de un estimador conjunto preciso ${ }^{14}$. No obstante, se calculó el área bajo la curva ROC resumen en estos tres estudios, con un valor de 0,93 , cercano a 1 , que se interpretó como un rendimiento diagnóstico aceptable de la prueba. En cuanto a la baja sensibilidad de la PET en la estadificación inicial de estos tumores, los autores sugieren que podría deberse a las limitaciones anatómicas de la prueba y a la eliminación urinaria del radiotrazador ${ }^{18} \mathrm{~F}-\mathrm{FDG}^{14}$. En los dos estudios que se referían a la reestadificación ${ }^{11,12}$, se obtuvo una sensibilidad conjunta de 0,87 (IC 95\%, 0,75-0,95) y una especificidad conjunta de 0,88 (IC 95\%, 0,47-1,00). En cuanto a los dos estudios que se ocupaban de la detección de metástasis $^{8,13}$, se obtuvo una sensibilidad conjunta de 0,72 (IC $95 \%, 0,56-0,85)$ y una especificidad conjunta de 0,70 (IC 95\%, 0,35-0,93). En el meta-análisis se alcanzaron las siguientes conclusiones:

(a) el papel más importante de la PET es la detección de metástasis;

(b) en la re-estadificación, la PET puede tener un papel importante en la valoración de masas detectadas con otras técnicas de imagen;

(c) en el diagnóstico inicial la PET muestra un rendimiento diagnóstico inferior a otras técnicas de imagen, en especial la TAC;

(d) las limitaciones de la PET son las lesiones de pequeño tamaño $(<1 \mathrm{~cm})$ y aquellas alteraciones que pueden estar enmascaradas por la eliminación urinaria del trazador; $\mathrm{y}$

(e) estas limitaciones quizás se puedan corregir con los nuevos equipos PET-TAC, aunque deberán realizarse estudios con estos nuevos sistemas que valoren su rendimiento diagnóstico ${ }^{14}$.

Los casos que se presentan (Figs. 1 y 2) son ejemplos de la aportación de la PET-TAC en la estadificación y reestadificación de pacientes con CCR. La eliminación urinaria del radiotrazador ${ }^{18} \mathrm{~F}$-FDG puede enmascarar la presencia de depósitos patológicos en pelvis, no sólo en el CCR sino también en tumores de vejiga, próstata $\mathrm{u}$ otros tumores pélvicos primarios o metastásicos. Sin embargo, una adecuada preparación del paciente y un protocolo de adquisición adecuado pueden mejorar el rendimiento diagnóstico de la PET con ${ }^{18} \mathrm{~F}$-FDG al reducir el número de falsos negativos (lesiones enmascaradas por actividad urinaria) y falsos positivos (acumulaciones de orina que pueden simular lesiones malignas). Para reducir la concentración de ${ }^{18} \mathrm{~F}$-FDG en la orina y su acumulación en el tracto urinario el paciente debe beber al menos $500 \mathrm{ml}$ de agua tras la administración de ${ }^{18} \mathrm{~F}$ FDG y orinar momentos antes de iniciar la adquisición de las imágenes. En casos de acumulaciones de dudosa valoración en pelvis está indicada la realización de imágenes tardías 2-3 horas más tarde tras la rehidratación del paciente con al menos otros $500 \mathrm{ml}$ de agua para forzar la diuresis y reducir aún más la concentración de ${ }^{18} \mathrm{~F}$-FDG en la orina. Se ha propuesto como una alternativa la administración de diuréticos (furosemida) para forzar la diuresis ${ }^{15,16}$, incluso la hidratación vía parenteral ${ }^{16}$. Otro aspecto a tener en cuenta es la preparación del intestino, ya que la administración de contraste oral diluido puede 


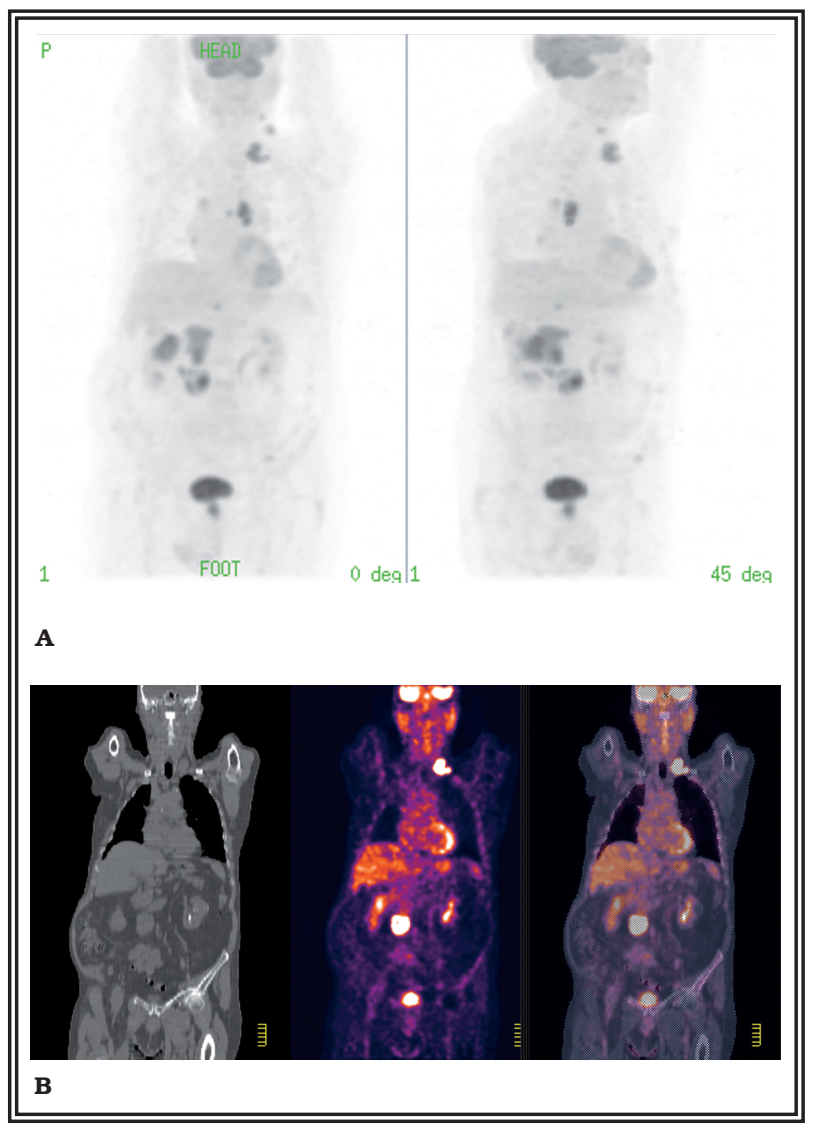

FIGURA 1. Paciente de 82 años con biopsia de masa renal derecha positiva para malignidad. En la PET-TAC con 18F-FDG para estadificación se detectaron lesiones de alta probabilidad de malignidad en la masa renal derecha y en adenopatias parahiliares renales homolaterales, interaortocavas, cervico-supraclaviculares izquierdas $y$ mediastinicas bilaterales $(A, B)$.

mejorar la definición de las asas intestinales sin inducir la aparición de artefactos significativos en la PET con ${ }^{18} \mathrm{~F}-\mathrm{FDG}^{15}$.

Ante las limitaciones de la PET con ${ }^{18} \mathrm{~F}-\mathrm{FDG}$ en el $\mathrm{CCR}$, recientemente se ha desarrollado un anticuerpo marcado con ${ }^{124}$ I que se une a la anhidrasa carbónica IX, denominado ${ }^{124}$ I-cG250. En un estudio prospectivo se realizó un estudio PET con ${ }^{124} \mathrm{I}$-cG250 en 26 pacientes con CCR previamente al tratamiento quirúrgico inicial ${ }^{2,17}$. La PET con ${ }^{124} \mathrm{I}-\mathrm{cG} 250$ demostró una sensibilidad del 94\% y una especificidad del $100 \%$. Los resultados son tan prometedores que los autores proponen que, en un futuro, puede ser una alternativa a la biopsia ${ }^{2,17}$.

\section{CÁNCER DE VEJIGA}

El cáncer de vejiga es el segundo tumor más frecuente del tracto genitourinario. El tipo histológico más frecuente es el carcinoma de células transicionales $(90 \%)^{18}$.

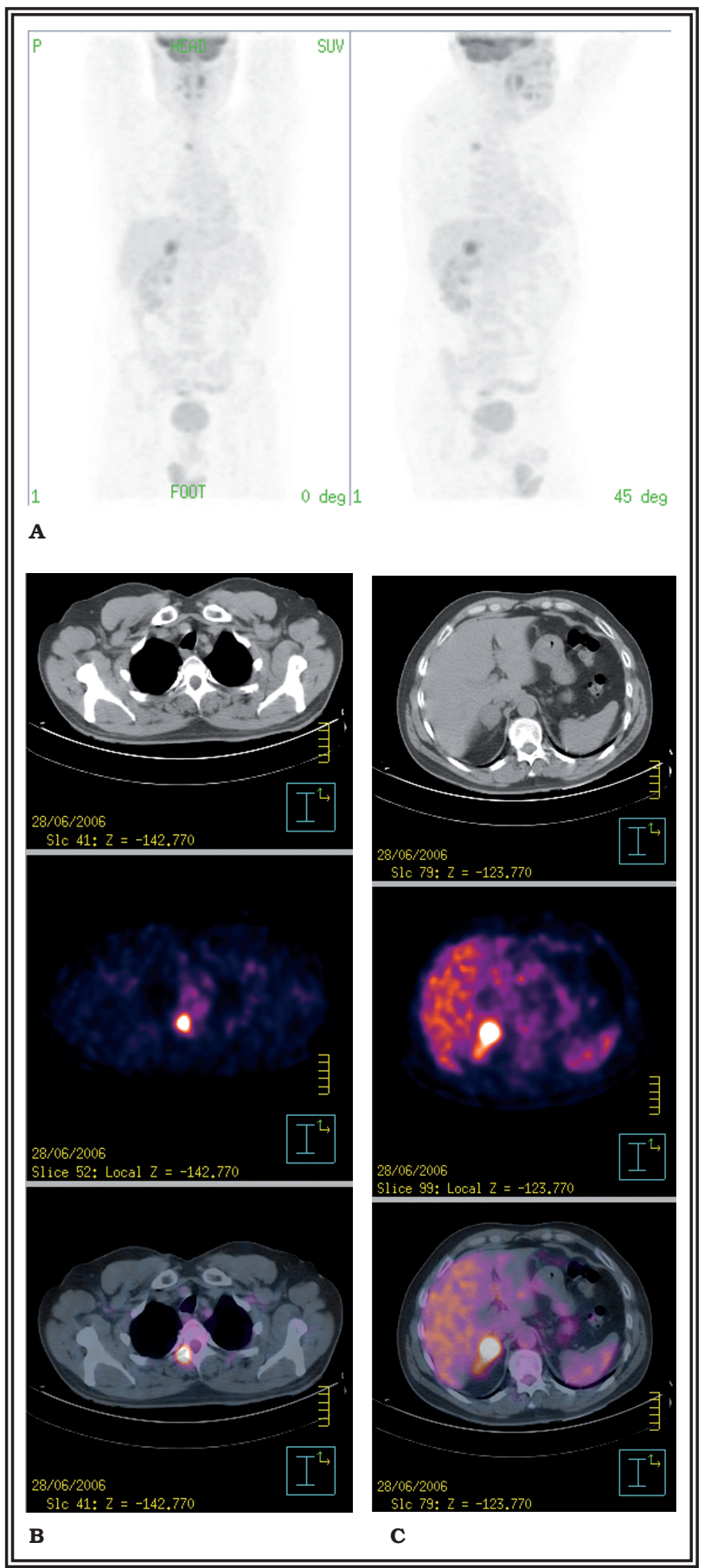

FIGURA 2. Paciente de 51 años con antecedentes de nefrectomía izquierda por adenocarcinoma renal hace 2 años, con una recidiva subcutánea torácica derecha resecada hace 1 mes. En la PETTAC con 18F-FDG para reestadificación se detectaron lesiones de alta probabilidad de malignidad en la apófisis transversa derecha de $D 4(A, B)$ y en la suprarrenal derecha $(A, C)$.

En el momento del diagnóstico, aproximadamente el $15 \%$ de los pacientes presentan extensión local fuera de la vejiga y/o metástasis a ganglios linfáticos regionales o a órganos a distancia ${ }^{18}$, siendo mayor la 
proporción de pacientes con enfermedad extendida (ganglionar o a distancia) en aquellos casos en los que el tumor invade la capa muscular $(25 \%$ con afectación ganglionar o a distancia) o cuando el tumor se extiende al tejido perivesical $(50 \%$ con afectación ganglionar o a distancia) ${ }^{19}$. Los pacientes con tumores invasivos frecuentemente son infraestadificados, lo que resalta la importancia de disponer de técnicas de imagen fiables ${ }^{18}$.

La TAC y la RM son los métodos diagnósticos utilizados habitualmente para la estadificación preoperatoria del cáncer de vejiga invasivo, aunque ambas técnicas presentan limitaciones significati$\operatorname{vas}^{18}$. Debido a su limitada sensibilidad, la TAC y la RM no son métodos diagnósticos precisos en los que basar las decisiones terapéuticas ${ }^{19}$. La TAC es el método más utilizado en esta situación, habiéndose descrito valores de exactitud diagnóstica del 64\%-92\% en la detección de la extensión del tumor más allá de la pared de la vejiga. En cuanto a la detección de afectación ganglionar metastásica, la TAC presenta valores de exactitud diagnóstica de $70 \%-90 \%$, con tasas de falsos negativos del $25 \%$ $40 \% 18,19$. La RM presenta valores de exactitud diagnóstica inferiores a la TAC, del 60\%-75\%. Tanto la TAC como la RM tienen una tendencia a sobreestadificar, debido a que se basan en cambios anatómicos que pueden deberse a una respuesta inflamatoria a la presencia del tumor o a biopsias recientes y no estar relacionadas con la presencia de infiltración maligna ${ }^{18,19}$. Además, la afectación ganglionar no necesariamente se acompaña de cambios en la forma o densidad de la adenopatía afecta; ganglios con diámetros menores de $1 \mathrm{~cm}$ son difíciles de detectar y su significación en TAC y RM es indeterminada $^{19}$. Por otro lado, la punción aspiración con aguja fina (PAAF) guiada por TAC aumenta la exactitud de la TAC en la estadificación, pero presenta un bajo valor predictivo negativo debido a errores en la toma de muestras ${ }^{19}$.

Hasta el momento se han publicado pocos estudios que analizan la aportación de la PET en el cáncer de vejiga. Esto puede ser debido, en parte, al hecho de que la interpretación de las imágenes PET ${ }^{18} \mathrm{~F}$-FDG es difícil debido a la eliminación urinaria del radiotrazador ${ }^{18} \mathrm{~F}$-FDG, que se acumula en riñones, uréteres y vejiga y que puede ocultar o enmascarar depósitos patológicos en lesiones malignas. Como se ha comentado anteriormente, se pueden aplicar protocolos específicos (imágenes tardías, diuresis forzada) que facilitan la valoración de la pelvis al reducir la concentración de la ${ }^{18} \mathrm{~F}$-FDG en las vías urinarias ${ }^{15,16}$. De esta forma se puede mejorar el rendimiento diagnóstico de la PET con ${ }^{18} \mathrm{~F}$ FDG en el estudio de tumores pélvicos.

En la estadificación preoperatoria del cáncer de vejiga con $\mathrm{PET}{ }^{18} \mathrm{~F}$-FDG, el estudio que presenta el mayor número de pacientes es el realizado por Bachor et al. ${ }^{20}$ En 64 pacientes con cáncer de vejiga se realizó una PET ${ }^{18} \mathrm{~F}$-FDG antes de llevar a cabo la cistectomía radical y linfadenectomía. Los resultados que obtuvieron en la estadificación regional o ganglionar con PET ${ }^{18} \mathrm{~F}$-FDG fueron una sensibilidad del 67\% (14/21), una especificidad del 86\% $(37 / 43)$ y una exactitud diagnóstica del $80 \%$, que fueron superiores a los obtenidos con los métodos convencionales de imagen ${ }^{20}$.

En el estudio realizado por Kosuda et al. se incluyeron 12 pacientes con cáncer de vejiga residual o recurrente confirmado histológicamente tras cirugía y/o radioterapia y se analizó la aportación de la PET ${ }^{18} \mathrm{~F}$-FDG en la valoración del tumor primario residual o recurrente, de la afectación ganglionar regional y en la detección de metástasis ${ }^{21}$. En cuanto al tumor primario, la PET ${ }^{18} \mathrm{~F}$-FDG fue verdadero positivo en 8 pacientes, es decir, mostró una sensibilidad del $67 \%$ con una tasa de falsos negativos del $33 \%{ }^{21}$. Respecto a la estadificación regional ganglionar, la PET ${ }^{18} \mathrm{~F}$-FDG detectó correctamente la afectación ganglionar en 2 de los 3 pacientes con extensión regional ${ }^{21}$. Finalmente, la PET ${ }^{18} \mathrm{~F}$-FDG tuvo un excelente rendimiento diagnóstico en la detección de enfermedad a distancia, ya que detectó correctamente el 100\% (17/17) de las lesiones metastásicas a distancia (pulmón, hueso, y estaciones ganglionares a distancia) ${ }^{21}$. Otro estudio con resultados similares al anterior es realizado por Heicappel et al., en el que se incluyeron 8 pacientes y la PET ${ }^{18}$ F-FDG detectó correctamente afectación ganglionar en 2 de los 3 ganglios histológicamente positivos, siendo la metástasis de menor tamaño de $9 \mathrm{~mm}$ de diámetro ${ }^{22}$.

Por tanto, los estudios presentados hasta el momento en la estadificación regional y a distancia muestran las limitaciones tanto de los métodos convencionales (TAC, RM, etc.) como de la PET ${ }^{18} \mathrm{~F}$ FDG. Una cuestión que se plantea es si se puede incrementar el rendimiento diagnóstico en la estadificación ganglionar y a distancia si se analizan conjuntamente la información funcional de la PET ${ }^{18} \mathrm{~F}$ - 
FDG y la información anatómica de la TAC o RM. Drieskens et al. analizaron esta cuestión en un estudio en el que realizaron una PET ${ }^{18} \mathrm{~F}-\mathrm{FDG}$ y una TAC en la estadificación preoperatoria de 55 pacientes con cáncer de vejiga invasivo no metastático ${ }^{19}$. Los estudios PET ${ }^{18} \mathrm{~F}$-FDG y TAC se realizaron en equipos diferentes. Se comparó el rendimiento diagnóstico en la estadificación ganglionar y a distancia de la PET ${ }^{18}$ F-FDG, con el rendimiento de la TAC, y con el rendimiento de ambas técnicas (PET ${ }^{18} \mathrm{~F}-\mathrm{FDG}$ y TAC) analizadas conjuntamente. La prueba de referencia se pudo aplicar en 40 de los 55 pacientes, en los que se encontró enfermedad en 15 de ellos (con 12 lesiones ganglionares y 8 metástasis), estando los 25 pacientes restantes libres de enfermedad regional y a distancia. La PET ${ }^{18}$ F-FDG y TAC analizadas conjuntamente mostraron una sensibilidad del 60\%, una especificidad del 88\%, y una exactitud diagnóstica del 78\%, superiores a los valores mostrados por la PET ${ }^{18} \mathrm{~F}$-FDG aislada con una sensibilidad del 53\%, una especificidad del $72 \%$, y una exactitud diagnóstica del $65 \%{ }^{19}$. Se encontraron discrepancias entre la PET ${ }^{18}$ F-FDG y TAC analizadas conjuntamente con la TAC aislada en 9/40 pacientes, resultando la PET ${ }^{18} \mathrm{~F}-\mathrm{FDG}$ y TAC analizadas conjuntamente correctas en 6 (15\%) de los 9 pacientes, con 3 verdaderos positivos y un verdadero negativo para metástasis, y dos verdaderos negativos para ganglios linfáticos ${ }^{19}$. Además, la PET ${ }^{18} \mathrm{~F}$ FDG y TAC analizadas conjuntamente tienen un valor pronóstico, ya que la supervivencia global de los pacientes con un resultado positivo fue significativamente menor que aquellos en los que presentaron un resultado negativo $(\mathrm{p}=0,003)$. Los autores concluyen que la integración de la información metabólica de la PET ${ }^{18}$ F-FDG con la TAC en la estadificación preoperatoria del cáncer de vejiga invasivo aporta una elevada exactitud diagnóstica y tiene valor pronóstico ${ }^{19}$.

Debido a que una de las principales limitaciones de la PET ${ }^{18}$ F-FDG en el cáncer de vejiga se debe a la excreción urinaria del trazador, una de las alternativas es la utilización de hidratación oral, diuréticos e imágenes tardías para reducir la concentración de la ${ }^{18}$ F-FDG en orina y facilitar la visualización de los tumores del tracto urinario. Recientemente, Anjos et al. publicaron un estudio en el que analizan el papel de la PET-TAC en la detección y re-estadificación del cáncer de vejiga cuando se obtienen imágenes tardías tras la aplicación de diu- réticos e hidratación oral ${ }^{23}$. En este estudio se incluyeron 17 pacientes ( 11 sin cistectomía, 6 con cistectomía total y derivación urinaria). En los 11 pacientes sin cistectomía, la PET-TAC detectó correctamente lesiones en vejiga en 6 (54\%) de ellos únicamente tras la realización de imágenes tardías tras la aplicación de furosemida e hidratación oral. En los otros cinco pacientes la PET-TAC fue negativa en vejiga, confirmándose dicho resultado ${ }^{23}$. En cuanto a la detección de afectación ganglionar, en 6 pacientes se detectó afectación de ganglios pélvicos en la imagen PET-TAC inicial (sin furosemida) y en otros 2 pacientes se detectaron ganglios pélvicos próximos a la vejiga únicamente en las imágenes tardías tras la aplicación de furosemida e hidratación oral ${ }^{23}$. La PET-TAC inicial (sin furosemida) detectó metástasis a distancia en 5 pacientes, mientras que en las imágenes tardías tras la aplicación de furosemida e hidratación oral se detectó una lesión prostática que no se había visualizado en el estudio PET-TAC inicial. En resumen, las imágenes tardías tras la aplicación de furosemida e hidratación oral modificaron el resultado de la PETTAC en 7 pacientes (6 lesiones recurrentes en vejiga, 2 ganglios pélvicos, 1 metástasis en próstata). Por tanto, se incrementó el estadio en 7 de 17 pacientes (41\%) tras la obtención de las imágenes $\operatorname{tardias}^{23}$. Por tanto, el rendimiento diagnóstico de la PET-TAC en el cáncer de vejiga mejora de forma importante mediante la realización de imágenes tardías tras la aplicación de furosemida e hidratación oral ${ }^{23}$. Recientemente, Jadvar et al. ${ }^{24}$ han publicado otro estudio que analiza la aportación de la PET-TAC en cáncer de vejiga. Realizaron 23 estudios PET-TAC en 18 pacientes con sospecha de recidiva o metástasis. Concluyen que la información de la PET-TAC modificó el manejo en el 17\% de los pacientes ${ }^{24}$.

Otras alternativas para tratar de evitar el problema que supone la eliminación urinaria del radiotrazador ha sido la utilización de otros radiotrazadores que no se eliminan vía urinaria, como la ${ }^{11} \mathrm{C}$-metionina y la ${ }^{11} \mathrm{C}$-colina. Ahlstrom et al. compararon la ${ }^{18} \mathrm{~F}$-FDG y la ${ }^{11} \mathrm{C}$-metionina y encontraron que la ${ }^{11} \mathrm{C}$-metionina era superior en la detección del tumor primario, aunque su sensibilidad en esta indicación alcanzaba sólo del $78 \%(18 / 23)^{25}$. En este estudio se observó que la captación del radiotrazador era proporcional al estadio o grado tumoral $\mathrm{y}$, por otra parte, que únicamente se visualizaban 
los tumores $>1 \mathrm{~cm}$ de diámetro ${ }^{25}$. No obstante, no existe evidencia de que este radiotrazador mejora la estadificación regional, por lo que no está indicada su utilización como método de rutina. ${ }^{25}$

En cuanto a la ${ }^{11} \mathrm{C}$-colina, de Jong et al. estudiaron 18 pacientes con cáncer de vejiga invasivo y demostraron que este radiotrazador presenta una mayor sensibilidad que la ${ }^{18}$ F-FDG en la estadificación de estos pacientes ${ }^{26}$. En este trabajo la PET con ${ }^{11} \mathrm{C}$-colina detectó enfermedad residual en 10/10 pacientes, mientras que tumores tempranos no invasivos no fueron detectados ${ }^{26}$. Recientemente se han publicado dos estudios que evaluaron el rendi- miento diagnóstico de la PET con ${ }^{11} \mathrm{C}$-colina en la detección preoperatoria de afectación ganglionar en el cáncer de vejiga ${ }^{27,28}$. Encontraron valores de sensibilidad entre 60\%-100\%, ligeramente superiores a los de la TAC como método aislado. En el estudio de Picchio et al. se incluyeron 27 pacientes con cáncer urotelial de vejiga tratados previamente con resección transuretral (para biopsia y/o tratamiento en tumores superficiales) que habían sido referidos para una cistectomía radical y linfadenectomía, y compararon la PET con ${ }^{11} \mathrm{C}$-colina con la $\mathrm{TAC}^{28}$. En cuanto a la valoración del tumor primario, la PET con ${ }^{11} \mathrm{C}$-colina detectó correctamente cáncer de veji-

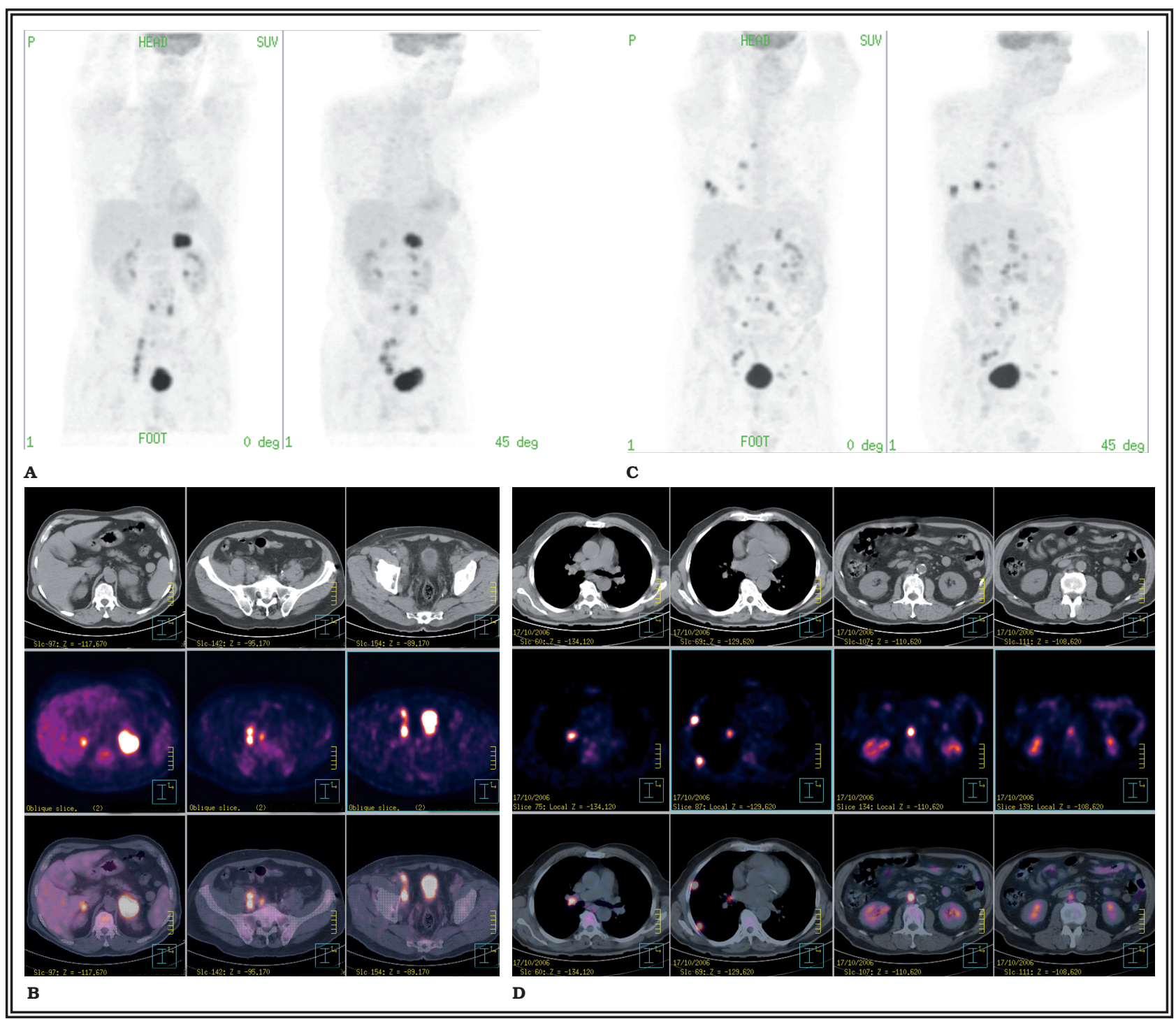

FIGURA 3. Paciente de 64 años con carcinoma de vejiga hace 4 años tratado con cirugía y quimioterapia. En revisión presentaba linfedema en miembro inferior derecho. La PET-TAC con 18F-FDG detectó múltiples lesiones malignas abdominopélvicas (A, B). Tras 3 meses de quimioterapia y tras una TAC sin hallazgos se realiza una PET-TAC, donde se observa la persistencia de las lesiones malignas y la aparición de nuevas lesiones torácicas y retroperitoneales (C, D), que sugería progresión de la enfermedad. 
ga residual en 24/25 pacientes (sensibilidad 96\%; exactitud diagnóstica 88,9\%), siendo superior a la TAC que detectó correctamente 21/25 pacientes (sensibilidad 84\%; especificidad 50\%; exactitud diagnóstica $81,5 \%$ ). Respecto a la afectación ganglionar, fue correctamente detectada mediante PET con ${ }^{11} \mathrm{C}$-colina en $5 / 8$ pacientes (sensibilidad 62,5\%; especificidad 100\%; exactitud diagnóstica $88,9 \%$ ), mientras que la TAC detectó correctamente 4/8 pacientes (sensibilidad 50\%; especificidad 68,4\%; exactitud diagnóstica 63\%). En la valoración de la afectación linfática, la PET con ${ }^{11} \mathrm{C}$-colina presentó una exactitud diagnóstica significativamente superior a la de la TAC $(\mathrm{p}<0,01)$. Aunque se trata de datos preliminares, la PET con ${ }^{11} \mathrm{C}$-colina tiene un rendimiento diagnóstico similar a la TAC en la detección de cáncer de vejiga residual tras resección transuretral, pero es superior a la TAC en la valoración de la afectación linfática ${ }^{28}$.

Los casos que se presentan (Figs. 3 y 4) son ejemplos de la aportación de la PET-TAC en la estadificación, reestadificación y valoración de la respuesta al tratamiento de pacientes con cáncer de vejiga.

\section{CÁNCER DE PRÓSTATA}

El cáncer de próstata es el tumor maligno más frecuente en varones en los países occidentales ${ }^{29}$. Este tumor muestra un comportamiento biológico variable, desde un tumor intraprostático indolente, clinicamente silente, a una neoplasia agresiva ${ }^{30}$, el $27 \%-53 \%$ de los varones desarrollan una recidiva

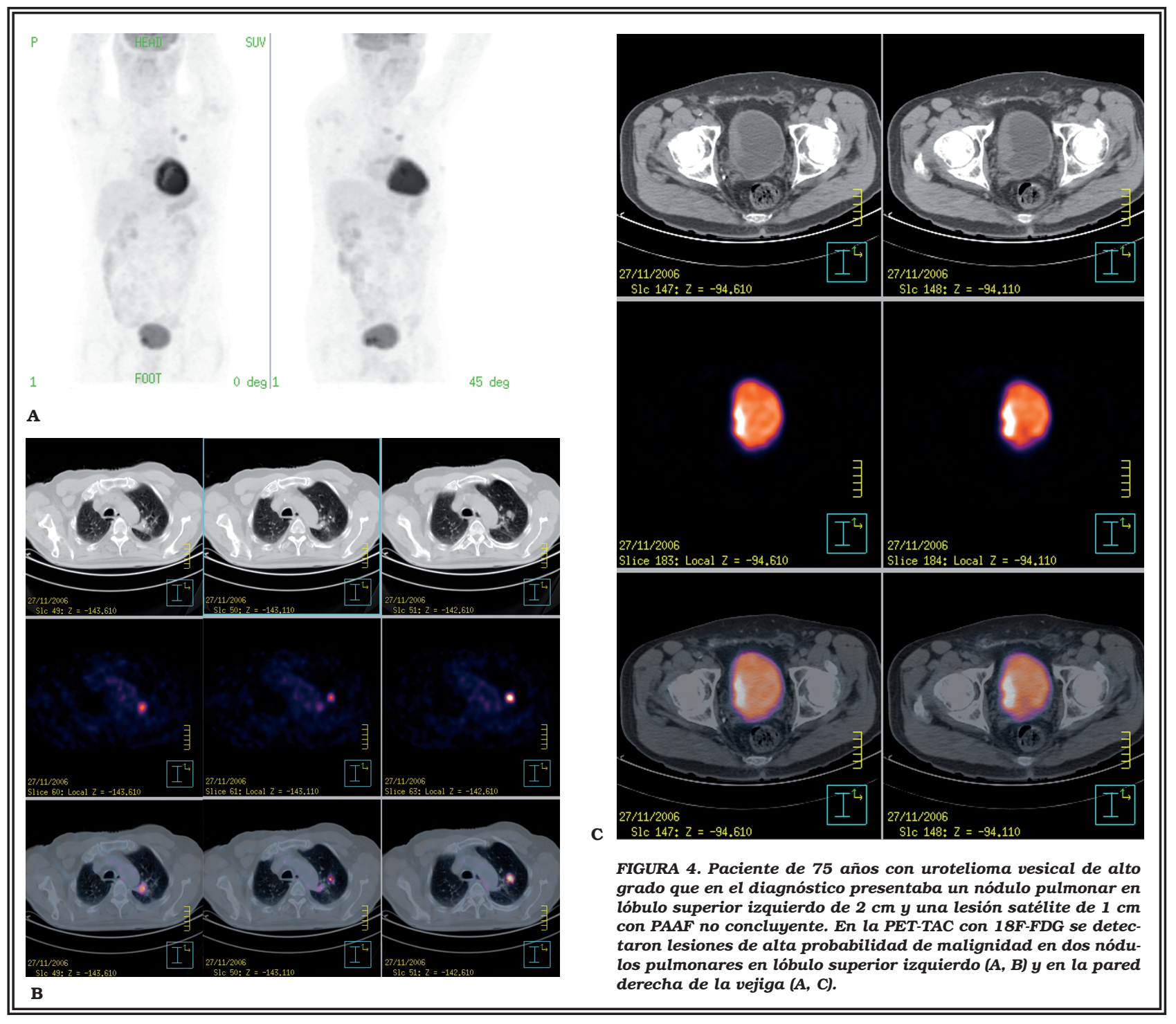


con elevación del antígeno prostático específico (PSA) hasta 10 años después de la prostatectomía radical. Tras la cirugía el PSA debe descender a valores indetectables en 3-4 semanas. Las recidivas de cáncer de próstata suelen ser asintomáticas, por lo que la detección de una recidiva se basa casi completamente en la detección de un incremento del PSA. Un valor de PSA de $0,2 \mathrm{ng} / \mathrm{ml}$ puede ser utilizado como nivel de corte para el diagnóstico de recidiva local. En el 50\% de pacientes se produce una recidiva local, y el otro $50 \%$ de pacientes presentan metástasis a distancia con o sin recidiva local. Debido a que el tratamiento y pronóstico de la enfermedad local o diseminada son diferentes, el diagnóstico de recidiva local es fundamental ${ }^{29}$.

A la hora de valorar el papel de la PET en el cáncer de próstata se deben analizar los diferentes radiotrazadores emisores de positrones disponibles. Un radiotrazador PET ideal sería aquel que permitiera identificar tanto el tumor primario como metástasis a distancia, mostrase un alto contraste entre el tumor y el tejido no tumoral, se pudiera producir con una sintesis radiofarmacéutica simple y rápida y pudiera ser marcado con un emisor de positrones con características de desintegración favorables y un periodo de semidesintegración de suficiente duración que permitiese su distribución comercial. Desafortunadamente en la actualidad no existe ningún radiotrazador PET que cumpla todas estas características, aunque hay algunos radiotrazadores que permiten localizar el cáncer de próstata con $\mathrm{PET}^{30,31}$.

A continuación se presentan los radiotrazadores PET que se han utilizado en la clínica y en investigación en cáncer de próstata: ${ }^{18} \mathrm{~F}-\mathrm{FDG},{ }^{11} \mathrm{C}$-colina, ${ }^{18} \mathrm{~F}$-colina, ${ }^{11} \mathrm{C}$-acetato, ${ }^{18} \mathrm{~F}$-acetato, ${ }^{18} \mathrm{~F}$-testosterona, ${ }^{18} \mathrm{~F}$-fluoruro, $\mathrm{y}^{11} \mathrm{C}$-metionina.

${ }^{18}$ F-FDG: La acumulación de ${ }^{18} \mathrm{~F}-\mathrm{FDG}$ en los tumores malignos se basa en el incremento del metabolismo de la glucosa y el aumento concomitante del número de proteínas transportadoras de glucosa en las membranas de las células malignas. Este proceso se ha demostrado in vitro en cultivos de células de cáncer de próstata, donde se ha observado correlación entre la captación de ${ }^{18}$ F-FDG y la malignidad del tumor primario medido por el Gleason y los niveles de PSA. Sin embargo, a pesar de estos resultados prometedores, la aplicación clínica de la PET con ${ }^{18} \mathrm{~F}$-FDG ha demostrado una eficacia limitada en el cáncer de próstata, tanto en la detección del tumor prostático como en la detección de metástasis ${ }^{30,32,33}$. La menor captación de ${ }^{18} \mathrm{~F}$-FDG en los tumores de próstata, en comparación con otros tumores, se ha atribuido a que estos tumores presentan un metabolismo más lento y menor expresión de proteínas transportadoras de glucosa ${ }^{30}$. Además del cáncer de próstata, otros tumores de metabolismo lento como sarcomas de bajo grado, linfomas de bajo grado, y carcinomas hepatocelulares bien diferenciados, muestran escasa avidez por la ${ }^{18} \mathrm{~F}-\mathrm{FDG}$; en todos estos tumores la PET con ${ }^{18} \mathrm{~F}$ FDG presenta una eficacia diagnóstica reducida ${ }^{34}$. En el cáncer de próstata existe otro factor añadido que reduce la eficacia diagnóstica de la PET con ${ }^{18} \mathrm{~F}$ FDG, que es la excreción urinaria de la ${ }^{18} \mathrm{~F}-\mathrm{FDG}$. La intensa actividad en uréteres y vejiga debido a la excreción urinaria puede enmascarar alteraciones en la próstata y en tejidos próximos (p.e. vesículas seminales), donde pueden existir metástasis locorregionales ${ }^{30}$. No obstante, como se ha comentado anteriormente, la aplicación de protocolos específicos (imágenes tardias, diuresis forzada) puede facilitar la valoración de lesiones pélvicas al reducir la concentración de la ${ }^{18} \mathrm{~F}$-FDG en la orina, mejorando el rendimiento diagnóstico de la PET en esta indicación. En resumen, la PET ${ }^{18} \mathrm{~F}$-FDG en cáncer de próstata no es útil para el diagnóstico, ya que no permite diferenciar cáncer de próstata de hiperplasia benigna de próstata, y presenta problemas en la detección de afectación ganglionar pélvica ${ }^{34}$. Por otra parte, la PET ${ }^{18}$ F-FDG muestra una baja sensibilidad (65\%) en la detección de metástasis óseas no tratadas, y es menos sensible que la gammagrafía ósea ${ }^{34,35}$.

${ }^{11}$ C-colina: La acumulación de colina en los tejidos se relaciona principalmente con la sintesis de fosfolipidos de la membrana celular. Las células del cáncer de próstata presentan una actividad incrementada de la colina-quinasa y niveles elevados de la fosforilcolina. La fosforilcolina es atrapada dentro de las células y convertida en fosfatidilcolina, que es uno de los principales componentes de la membrana celular. La proliferación celular incontrolada acompañada de la síntesis de membranas en algunos tejidos malignos es la causa de la acumulación de colina. Sin embargo, en el cáncer de próstata la captación in vivo de ${ }^{11} \mathrm{C}$-colina no se correlaciona con los índices de proliferación celular, lo que sugiere que otros procesos diferentes de la proliferación celular podrían ser responsables de la acumulación de ${ }^{11} \mathrm{C}$-colina ${ }^{30}$. 
La utilidad de la PET con ${ }^{11} \mathrm{C}$-colina en el cáncer de próstata se ha demostrado en más de 20 estudios publicados hasta el momento, principalmente en la detección de recidivas ${ }^{30}$. Sin embargo, el papel de la PET con ${ }^{11} \mathrm{C}$-colina en la valoración del tumor primario intraprostático y en la estadificación linfática del cáncer de próstata no está claro, y son necesarios nuevos estudios debido a que los escasos trabajos publicados presentan resultados discordantes ${ }^{36}$.

La principal desventaja de la ${ }^{11} \mathrm{C}$-colina es $\mathrm{su}$ periodo de semidesintegración corto (20 minutos), por lo que se requiere la presencia de un ciclotrón cercano para poder realizar estos estudios e impide su distribución a centros PET alejados.

${ }^{18}$ F-colina: La ${ }^{18} \mathrm{~F}$-colina se desarrolló como alternativa a la ${ }^{11} \mathrm{C}$-colina, para evitar el inconveniente del corto periodo de semidesintegración del ${ }^{11} \mathrm{C}$, y aumentar las posibilidades de distribución ${ }^{30,36}$. Algunos estudios han sugerido que la exactitud diagnóstica de la ${ }^{18} \mathrm{~F}$-colina es comparable a la de la ${ }^{11} \mathrm{C}$ colina $^{37}$, aunque todavía no se ha publicado ningún estudio que compare ambos radiotrazadores en la misma muestra de pacientes ${ }^{36}$.

${ }^{11} \mathrm{C}$-acetato: $\mathrm{El}{ }^{11} \mathrm{C}$-acetato es un radiotrazador de la sintesis de ácidos grasos. Aunque el mecanismo de captación en las neoplasias no está del todo claro, se ha postulado que la actividad metabólica en los tumores se produce en un microambiente con bajas concentraciones de oxígeno, asociado a un aumento de las reservas de ácidos grasos que acompaña a la proliferación celular acelerada; la captación también podría estar relacionada con las alteraciones hormonales asociadas al cáncer de prósta$\mathrm{ta}^{38}$. En una revisión reciente sobre el papel de la PET con ${ }^{11} \mathrm{C}$-acetato en pacientes con cáncer de próstata en la detección de enfermedad local, ganglionar y afectación ósea, se analizaron 5 estudios que incluían 154 pacientes $^{38}$. Se observó que los estudios publicados incluían muestras de pacientes pequeñas y heterogéneas, presentaban múltiples defectos metodológicos (fundamentalmente sesgos de inclusión y de confirmación) y no permitían llegar a una conclusión sobre el papel de la PET con ${ }^{11} \mathrm{C}$-acetato en estos pacientes. No obstante, la evidencia disponible sugiere que la PET con ${ }^{11} \mathrm{C}$-acetato es más sensible que la PET con ${ }^{18} \mathrm{~F}-\mathrm{FDG}$ en la detección de recidiva ${ }^{30}$. Esta mayor sensibilidad se acompaña de baja especificidad, debido a que el ${ }^{11} \mathrm{C}$-acetato también se acumula en tejido hiperplásico $^{34}$. Para poder explicar estos resultados es nece- sario analizar las características farmacodinámicas del ${ }^{11} \mathrm{C}$-acetato, aunque hasta el momento no se han publicado estudios al respecto ${ }^{34}$. El conocimiento de las propiedades farmacodinámicas del ${ }^{11} \mathrm{C}$-acetato y de los demás radiotrazadores podría permitir incrementar la exactitud diagnóstica de la PET mediante la realización de estudios con múltiples radiotrazadores y estudios dinámicos ${ }^{34}$.

Al disponer de diferentes radiotrazadores se plantea la cuestión de cuál tiene un rendimiento diagnóstico superior. En la actualidad la evidencia disponible sobre la comparación del rendimiento de los diferentes radiotrazadores es escasa y de baja calidad. En concreto, sólo se ha publicado un estudio que compara directamente la PET con ${ }^{11} \mathrm{C}$-colina y la PET con ${ }^{11} \mathrm{C}$-acetato en un mismo grupo de 12 pacientes ${ }^{39}$. En este estudio la muestra de pacientes era muy pequeña y heterogénea, ya que las indicaciones por las que se realizaban los estudios PET con ambos radiotrazadores era variada (estadificación primaria, sospecha de recidiva y seguimiento) ${ }^{36,39}$. Este estudio muestra resultados prácticamente idénticos con ${ }^{11} \mathrm{C}$-colina $\mathrm{y}$ ${ }^{11} \mathrm{C}$-acetato ${ }^{30,36,39}$. No obstante, estos resultados deben ser valorados con cautela, debido a la baja calidad de la evidencia por los defectos metodológicos mencionados.

${ }^{18}$ F-acetato: $\mathrm{El}$ acetato también se ha marcado con ${ }^{18} \mathrm{~F}$ para facilitar su distribución y aplicación clínica, al estar marcado con un isótopo de periodo de semidesintegración más largo. Sin embargo, hasta el momento no se han desarrollado métodos de producción eficientes. Por otra parte, todavía no existe evidencia de calidad que permita valorar el papel de la PET con ${ }^{18} \mathrm{~F}$-acetato en el cáncer de próstata ${ }^{30}$.

${ }^{18}$ F-testosterona: El papel del receptor androgénico en el cáncer de próstata es conocido y prácticamente todos los pacientes inicialmente responden a la terapia hormonal con anti-andrógenos. Para poder monitorizar la respuesta a esta terapia, se han desarrollado radiotrazadores con afinidad por el receptor androgénico. El radiotrazador marcado con un emisor de positrones es el ${ }^{18} \mathrm{~F}$-dihidrotestosterona. El papel de este radiofármaco sería la identificación de resistencia a la terapia hormonal ablativa. Actualmente se están llevando a cabo estudios para determinar si puede ser utilizado en esta indicación ${ }^{30}$.

${ }^{18}$ F-fluoruro: El papel del ${ }^{18} \mathrm{~F}$-fluoruro es el estudio del metabolismo óseo. Aunque permite obtener estudios de alta calidad, el elevado coste de la PET 
con este radiotrazador impide su aplicación clínica en lugar de los rastreos óseos convencionales ${ }^{30}$.

${ }^{11}$ C-metionina: La ${ }^{11} \mathrm{C}$-metionina es un marcador del transporte de aminoácidos y ha sido utilizado como un radiotrazador no específico para detectar patología maligna. Datos preliminares sugieren un posible papel de la ${ }^{11} \mathrm{C}$-metionina en el cáncer de próstata $^{30}$.

El papel de la PET en el cáncer de próstata en el diagnóstico inicial, estadificación, detección de recidiva y valoración de la respuesta al tratamiento se tratará a continuación.

Diagnóstico inicial: La PET con ${ }^{18}$ F-FDG no es útil en la detección del tumor primario de próstata, como se ha comentado anteriormente. La colina y el acetato marcados con emisores de positrones muestran patrones de distribución similares con acumulación tanto en el cáncer de próstata como en la hipertrofia prostática benigna. Aunque parece que los tumores malignos pueden mostrar mayor avidez para cualquiera de estos radiotrazadores (colina y acetato) en comparación con los procesos benignos de próstata, las diferencias no son lo suficientemente importantes para poder discriminar ambas patologías. La incapacidad para distinguir entre procesos benignos y malignos de próstata limita de forma importante la utilidad clínica de estos radiotrazadores (colina y acetato) en la valoración de la enfermedad in situ. Además, cuando se ha comparado la ${ }^{11} \mathrm{C}$-colina con el estudio anatomopatológico tras biopsia se ha observado que la PET con ${ }^{11} \mathrm{C}$-colina presenta un número significativo de resultados falsos negativos, que pueden ser debidos a pequeños focos tumorales in situ y baja avidez por la ${ }^{11} \mathrm{C}$-colina. Por todo ello, la evidencia disponible sugiere que la PET con los radiofármacos disponibles en la actualidad tiene poco que ofrecer en el diagnóstico del tumor primario de próstata ${ }^{30}$.

Estadificación: La PET con ${ }^{18} \mathrm{~F}-\mathrm{FDG}$ no es útil en la estadificación del cáncer de próstata, ya que presenta una sensibilidad baja debido a que la mayoría de los tumores primarios, adenopatías y lesiones óseas muestran escasa avidez por la ${ }^{18} \mathrm{~F}$ FDG. Otro factor que limita el papel de la PET en la evaluación de la extensión local de la enfermedad, en la estadificación linfática regional y en la detección de metástasis óseas es su resolución espacial, que actualmente es de alrededor de $6 \mathrm{~mm}^{30}$. En cuanto a la PET con ${ }^{11} \mathrm{C}$-colina y ${ }^{11} \mathrm{C}$-acetato, toda- vía hay pocos estudios publicados que analicen su papel en la estadificación linfática regional y en la detección de metástasis óseas en el cáncer de próstata. Estos trabajos muestran valores favorables de sensibilidad y especificidad, aunque incluyen muestras pequeñas de pacientes y se requieren nuevos estudios que aporten evidencia científica de calidad. La evidencia disponible actualmente sugiere que la PET con ${ }^{11} \mathrm{C}$-colina y ${ }^{11} \mathrm{C}$-acetato podría ser un método preciso en la estadificación preoperatoria del cáncer de próstata, y quizá tenga un papel en la estadificación linfática no invasiva del cáncer de próstata $^{30}$

Detección de recidiva: La recidiva del cáncer de próstata es sospechada ante elevaciones del PSA, que suele presentarse sin síntomas ni otros hallazgos clínicos. La gammagrafía ósea es el método de elección para excluir la presencia de metástasis óseas, aunque la probabilidad preprueba de enfermedad es muy baja en pacientes con PSA <40 $\mathrm{ng} / \mathrm{ml}^{30}$. La PET con ${ }^{18} \mathrm{~F}$-FDG muestra una sensibilidad baja y puede presentar falsos negativos para el foco de recidiva en hasta el 50\% de casos. Los resultados de la PET con ${ }^{18} \mathrm{~F}-\mathrm{FDG}$ se pueden mejorar si se seleccionan aquellos pacientes con valores de PSA más elevados. No obstante, con la evidencia disponible no se puede recomendar la PET con ${ }^{18} \mathrm{~F}$ FDG como prueba de rutina para detectar recidiva en el cáncer de próstata y es preferible la utilización de otros radiotrazadores como la colina o el acetato, si estuvieran disponibles ${ }^{30}$.

La PET con ${ }^{11} \mathrm{C}$-colina detecta correctamente la localización de la recidiva en el cáncer de próstata en el 47\%-54\% de los pacientes ${ }^{30,40}$. La exactitud diagnóstica de la PET con ${ }^{11} \mathrm{C}$-colina es mayor que la de la PET con ${ }^{18}$ F-FDG. Además, una PET con ${ }^{11} \mathrm{C}$-colina negativa para recidiva es un indicador de buen pronóstico, ya que se asoció a valores estables del PSA durante más de un año de seguimiento ${ }^{40}$.

En cuanto a la PET con ${ }^{11} \mathrm{C}$-acetato, como se ha comentado anteriormente, la evidencia disponible sugiere que la PET con ${ }^{11} \mathrm{C}$-acetato es más sensible que la $\mathrm{PET}$ con ${ }^{18} \mathrm{~F}-\mathrm{FDG}$ en la detección de recidi$\mathrm{va}^{30}$, aunque estos resultados deben tomarse con cautela debido a la escasa calidad metodológica de los estudios publicados hasta el momento ${ }^{38}$.

La disponibilidad de diferentes radiotrazadores PET plantea la cuestión de cuál es el que proporciona un mayor rendimiento diagnóstico en cada indicación. La evidencia presentada hasta el 


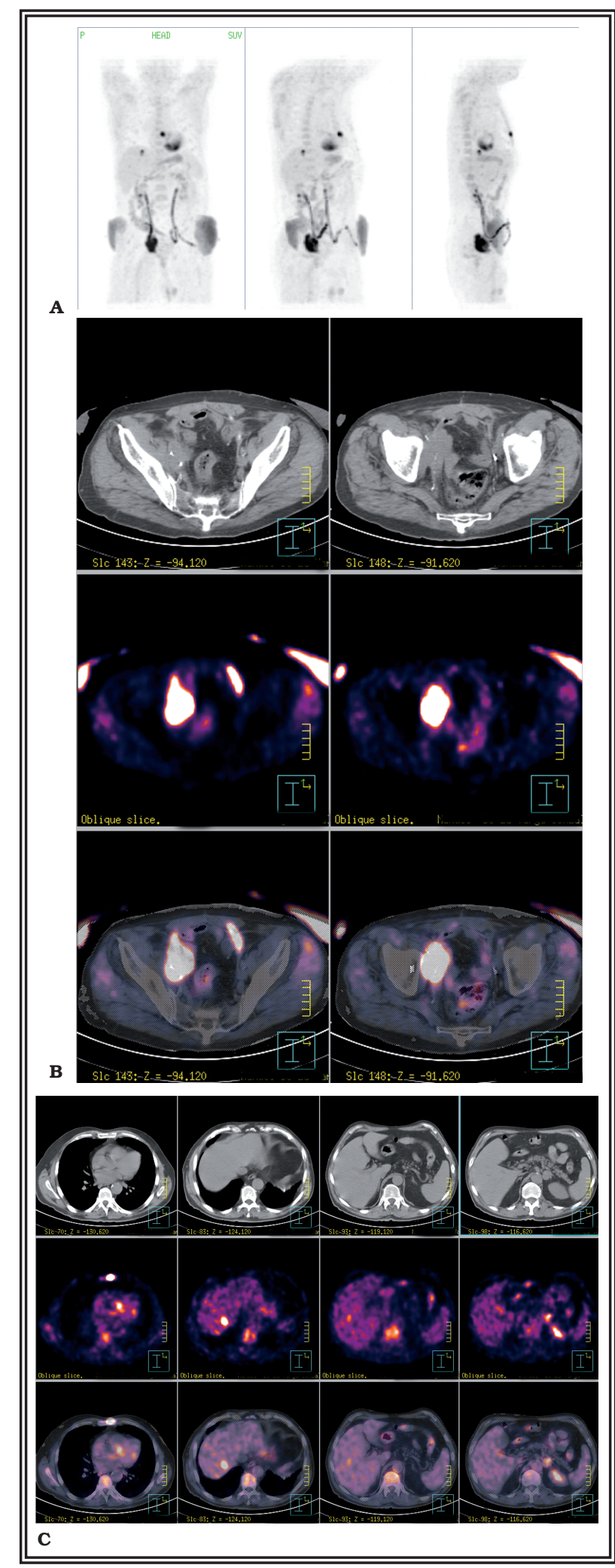

FIGURA 5. Paciente de 65 años con carcinomas vesical y prostático diagnosticados hace 2 años, tratado con cistectomía y prostatectomía radical. Se realizó una PET-TAC para descartar recidiva. En la PET-TAC con 18F-FDG se detectaron lesiones de alta probabilidad de malignidad en masa en hemipelvis derecha (A, $B$ ), en suprarrenal izquierda, en lesión en cúpula hepática (segmento VII) y en cuerpo esternal $(A, C)$.

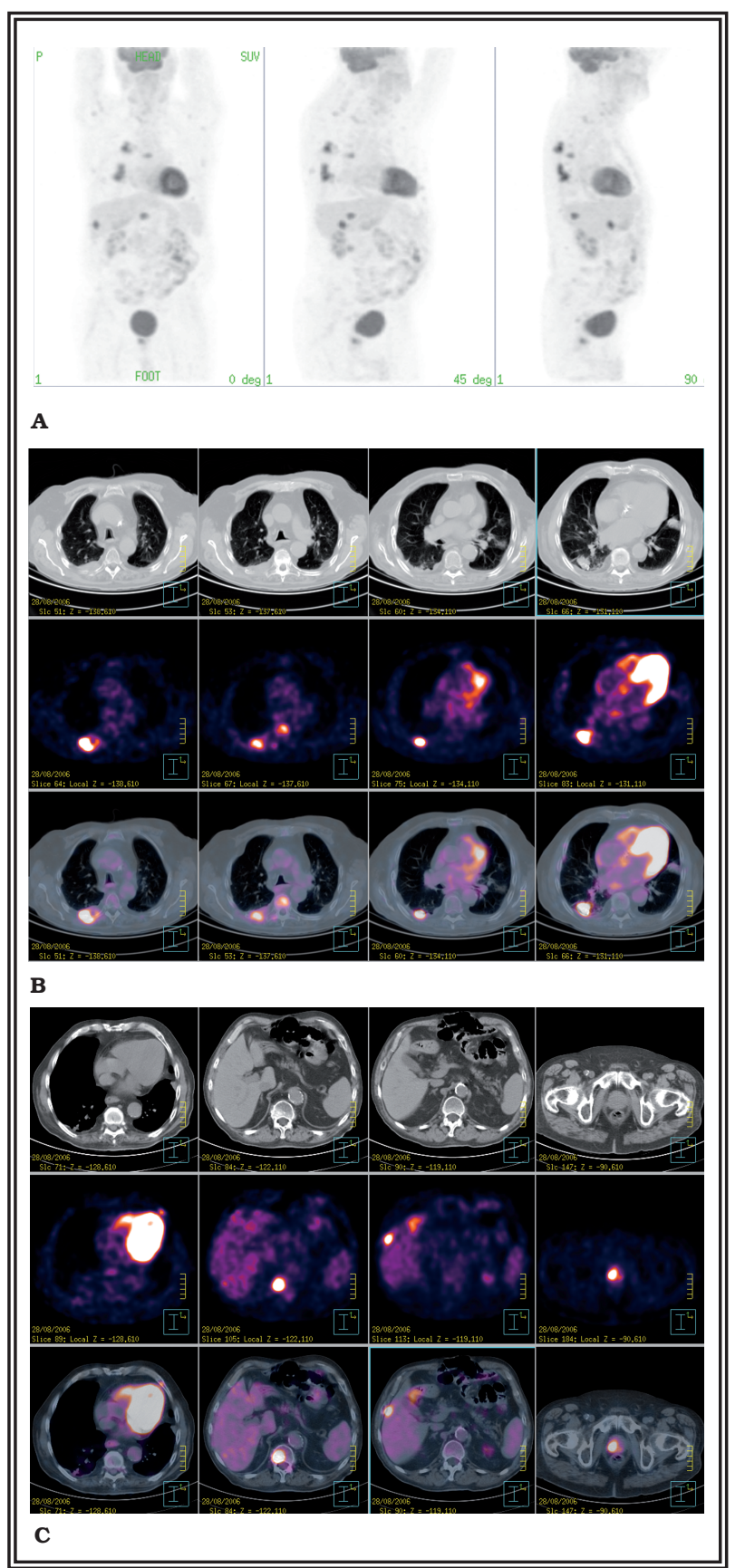

FIGURA 6. Paciente de 77 años con carcinoma de próstata hace 9 años (tratado con radioterapia) y carcinoma de colon operado hace 5 años. Intervenido por dos nódulos pulmonares hace 1 año. En el momento del estudio presentaba dolor costal derecho. Se realizó una PET-TAC con 18F-FDG. En la PET-TAC se detectaron lesiones malignas en próstata, en nódulo pulmonar derecho, en higado (segmento $V$ ), en múltiples estructuras óseas, y en pleura pulmonar adyacente a $5^{a}$ y $6^{a}$ costillas derechas $(A, B, C)$.

momento muestra la superioridad de la ${ }^{11} \mathrm{C}$-colina frente a la ${ }^{18} \mathrm{~F}-\mathrm{FDG}$ en la detección de recidiva. No obstante, todavía no hay datos concluyentes sobre si debe utilizarse la ${ }^{11} \mathrm{C}$-colina o el ${ }^{11} \mathrm{C}$-acetato en esta indicación. Como se ha descrito anteriormente, el único estudio disponible que realiza una 
comparación directa del rendimiento diagnóstico de ambos radiotrazadores PET en el mismo grupo de pacientes incluye sólo $12 \operatorname{casos}^{39}$. Teniendo en cuenta que los resultados de este trabajo deben ser valorados con cautela debido a la baja calidad de la evidencia $^{36}$, este estudio muestra resultados prácticamente idénticos con ${ }^{11} \mathrm{C}$-colina y ${ }^{11} \mathrm{C}$-acetato ${ }^{30,36,39}$.

Por otra parte, la disponibilidad de múltiples radiotrazadores plantea una cuestión importante, que es cuál es la indicación para realizar una PET en estos pacientes. En primer lugar, se ha discutido sobre el valor de PSA a partir del cual debe realizarse una PET en pacientes con sospecha de recidiva de cáncer de próstata. La evidencia científica no es concluyente, ya que los estudios publicados presentan resultados contradictorios. Mientras que en algunos trabajos se observa que la probabilidad de detección de lesiones con PET con ${ }^{11} \mathrm{C}$-colina es mayor en pacientes con PSA > $3 \mathrm{ng} / \mathrm{ml}$ o que existe una relación directa entre el nivel de PSA y la detección de lesiones, en otros estudios no se ha observado ninguna asociación entre el valor de PSA y la detección de lesiones con $\mathrm{PET}^{30}$. En este sentido, algunos autores opinan que la elección del radiotrazador (colina o acetato marcados con ${ }^{18} \mathrm{~F}$ o ${ }^{11} \mathrm{C}$ ) probablemente no lleve a resultados significativamente diferentes. Sin embargo, consideran que es mucho más relevante que se realice la PET a estos pacientes basándose en una indicación clínica apropiada. Aseguran que ésta es la única forma de incrementar la sensibilidad de la PET en pacientes con cáncer de próstata ${ }^{36}$.

En resumen, en pacientes con cáncer de próstata la PET con ${ }^{11} \mathrm{C}$-colina y ${ }^{11} \mathrm{C}$-acetato podría estar indicada en la detección de recidiva. En el futuro, cuando se disponga de más evidencia científica probablemente se pueda confirmar la eficacia de estos nuevos radiotrazadores en esta indicación ${ }^{30}$.

Valoración de la respuesta al tratamiento: Los pacientes con cáncer de próstata primario o metastático inicialmente responden a la terapia hormonal con anti-andrógenos, aunque en una fase más tardía de la enfermedad el tumor se puede volver independiente de los andrógenos y más agresivo. Algunos autores opinan que la PET con ${ }^{18} \mathrm{~F}-\mathrm{FDG}$ quizá pueda ser utilizada en la monitorización del tratamiento en el cáncer de próstata, basándose en estudios experimentales en animales y datos preliminares en pacientes; no obstante, se trata de especulaciones ya que no existe evidencia científica sufi- ciente. En la actualidad, la evidencia científica indica que la PET con ${ }^{18} \mathrm{~F}$-dihidrotestosterona quizá sea útil en la monitorización del tratamiento en el cáncer de próstata ${ }^{30}$.

Los casos que se presentan (Figs. 5 y 6) son ejemplos de la aportación de la PET-TAC en la estadificación y reestadificación de pacientes con cáncer de próstata.

\section{CONCLUSIONES}

La PET ha demostrado su utilidad en el diagnóstico, estadificación y valoración de la respuesta al tratamiento en diversos tipos de tumores. En el caso de los tumores del tracto urinario y del cáncer de próstata su rendimiento diagnóstico ha sido menor debido a la eliminación urinaria del trazador que puede enmascarar la presencia de lesiones. No obstante, deben aplicarse protocolos específicos (imágenes tardias, diuresis forzada) que reducen la concentración de ${ }^{18} \mathrm{~F}-\mathrm{FDG}$ en orina y mejoran el rendimiento diagnóstico de la PET con ${ }^{18} \mathrm{~F}-\mathrm{FDG}$ en la valoración de lesiones pélvicas. Además, el cáncer de próstata es un tumor de bajo grado que muestra escasa avidez por la ${ }^{18} \mathrm{~F}$-FDG. A pesar de estas limitaciones, con la PET se ha planteado nuevas e interesantes posibilidades diagnósticas. La disponibilidad de equipos PET-TAC ha mejorado su rendimiento diagnóstico, al disponer de la información funcional o metabólica junto a la información estructural o anatómica. Por otra parte, el desarrollo de nuevos radiotrazadores que permiten marcar otros procesos moleculares y que son metabolizados y eliminados por vías diferentes de la vía urinaria supone una ventaja importante respecto a la ${ }^{18} \mathrm{~F}$ FDG. Estos nuevos radiotrazadores ha proporcionado resultados interesantes en estos tumores, que van a incentivar el desarrollo de nuevas moléculas que puedan ser utilizadas en oncología.

\section{REFERENCIAS}

1. Vasudevan A, Davies RJ, Shannon BA, Cohen RJ. Incidental renal tumours: the frequency of benign lesions and the role of preoperative core biopsy. BJU Int. 2006;97:946-949.

2. Divgi CR, Pandit-Taskar N, Jungbluth AA, Reuter VE, Gönen M, Ruan S, et al. Preoperative characterisation of clear-cell renal carcinoma using iodine-124-labelled antibody chimeric G250 (124IcG250) and PET in patients with renal masses: a phase I trial. Lancet Oncol. 2007;8(4):304-310.

3. Linehan WM, Walther MM, Zbar B. The genetic basis of cancer of the kidney. J Urol. 2003; 170(6 Pt 1):2163-2172.

4. Motzer RJ, Bacik J, Mariani T, Russo P, Mazumdar M, Reuter V. Treatment outcome and survival associated with metastatic renal cell carcinoma of non-clear cell histology. J Clin Oncol. 2002; 20(9): 2376-2381. 
5. Powles T, Murray I, Brock C, Oliver T, Avril N. Molecular positron emission tomography and PET/CT imaging in urological malignancies. Eur Urol. 2007;51(6):1511-1520.

6. Powles T, Ell PJ. Does PET imaging have a role in renal cancers after all?. Lancet Oncol. 2007;8(4):279-281.

7. Kang DE, White RL Jr, Zuger JH, Sasser HC, Teigland CM. Clinical use of fluorodeoxyglucose F 18 positron emission tomography for detection of renal cell carcinoma. J Urol. 2004;171(5):1806-1809.

8. Aide N, Cappele O, Bottet P, Bensadoun H, Regeasse A, Comoz F, et al. Efficiency of [(18)F]FDG PET in characterising renal cancer and detecting distant metastases: a comparison with CT. Eur J Nucl Med Mol Imaging. 2003;30(9):1236-1245.

9. Ramdave S, Thomas GW, Berlangieri SU, Bolton DM, Davis I, Danguy HT, et al. Clinical role of F-18 fluorodeoxyglucose positron emission tomography for detection and management of renal cell carcinoma. J Urol. 2001;166(3):825-830.

10. Goldberg MA, Mayo-Smith WW, Papanicolau N, Fischman AJ, Lee MJ. FDG PET characterization of renal masses: preliminary experience. Clin Radiol. 1997;52(7):510-515.

11. Jadvar H, Kherbache HM, Pinski JK. Diagnostic role of [F-18]-FDG positron emission tomography in restaging renal cell carcinoma. Clin Nephrol. 2003;60(6):395-400.

12. Safaei A, Figlin R, Hoh CK, Silverman DH, Seltzer M, Phelps ME, et al. The usefulness of F-18 deoxyglucose whole-body positron emission tomography (PET) for re-staging of renal cell cancer. Clin Nephrol. 2002; 57(1):56-62.

13. Majhail NS, Urbain JL, Albani JM, Kanvinde MH, Rice TW, Novick AC, et al. F-18 fluorodeoxyglucose positron emission tomography in the evaluation of distant metastases from renal cell carcinoma. J Clin Oncol. 2003;21(21):3995-4000.

14. Martínez de Llano SR, Delgado-Bolton RC, Jiménez-Vicioso A, PérezCastejón MJ, Carreras Delgado JL, Ramos E, et al. Meta-análisis sobre el rendimiento diagnóstico de la tomografía por emisión de positrones con 18F-FDG en el carcinoma de células renales. Rev Esp Med Nucl. 2007;26(1):19-29.

15. Subhas N, Patel PV, Pannu HK, Jacene HA, Fishman EK, Wahl RL. Imaging of pelvic malignancies with in-line FDG PET-CT: case examples and common pitfalls of FDG PET. Radiographics. 2005;25(4): 1031-1043.

16. Kamel EM, Jichlinski P, Prior JO, Meuwly JY, Delaloye JF, Vaucher $\mathrm{L}$, et al. Forced diuresis improves the diagnostic accuracy of $18 \mathrm{~F}$ FDG PET in abdominopelvic malignancies. J Nucl Med. 2006;47(11):1803-1807.

17. Larson SM, Schöder H. Advances in positron emission tomography applications for urologic cancers. Curr Opin Urol. 2008;18(1):65-70.

18. Seltzer M, Shvarts O. PET in bladder, renal, and prostate cancer. En: Oehr p, Biersack HJ, Coleman RE, editors. PET and PET-CT in Oncology. 1st edition. Berlin-Heidelberg: Springer-Verlag Publishers; 2004. p. 243-9.

19. Drieskens O, Oyen R, Van Poppel H, Vankan Y, Flamen $P$, Mortelmans L. FDG-PET for preoperative staging of bladder cancer. Eur J Nucl Med Mol Imaging. 2005;32(12):1412-1417.

20. Bachor R, Kotzerke J, Reske SN, Hautmann R. Lymph node staging for urinary bladder carcinoma with positron emission tomography. Urologe A. 1999;38(1):46-50.

21. Kosuda S, Kison PV, Greenough R, Grossman HB, Wahl RL. Preliminary assessment of fluorine-18 fluorodeoxyglucose positron emission tomography in patients with bladder cancer. Eur $\mathrm{J}$ Nucl Med. 1997;24(6):615-620.

22. Heicappell R, Müller-Mattheis V, Reinhardt M, Vosberg H, Gerharz $\mathrm{CD}$, Muller-Gartner $\mathrm{H}$, et al. Staging of pelvic lymph nodes in neoplasms of the bladder and prostate by positron emission tomography with 2-(18F)-2-deoxy-D-glucose. Eur Urol. 1999;36(6):582587.

23. Anjos DA, Etchebehere E, Ramos CD, Santos AO, Albertotti C, Camargo EE. 18F-FDG PET/CT delayed images after diuretic for restaging invasive bladder cancer. J Nucl Med. 2007;48(5):764-770.
24. Jadvar H, Quan V, Henderson RW, Conti PS. [F-18] Fluorodeoxyglucose PET and PET-CT in diagnostic imaging evaluation of locally recurrent and metastatic bladder transitional cell carcinoma. Int J Clin Oncol 2008;13(1):42-47.

25. Ahlstrom H, Malmstrom PU, Letocha H, Andersson J, Langstrom B, Nilsson S. Positron emission tomography in the diagnosis and staging of urinary bladder cancer. Acta Radiol. 1996;37(2):180-185.

26. de Jong IJ, Pruim J, Elsinga PH, Jongen MM, Mensink HJ, Vaalburg W. Visualisation of bladder cancer using 11C-choline PET: first clinical experience. Eur J Nucl Med Mol Imaging. 2002;29(10):1283-1288.

27. Gofrit ON, Mishani E, Orevi M, Klein M, Freedman N, Pode D, et al. Contribution of $11 \mathrm{C}$-choline positron emission tomography/computerized tomography to preoperative staging of advanced transitional cell carcinoma. J Urol. 2006;176(3): 940-944.

28. Picchio M, Treiber U, Beer AJ, Metz S, Bössner P, van Randenborgh $\mathrm{H}$, et al. Value of $11 \mathrm{C}$-choline PET and contrast-enhanced CT for staging of bladder cancer: correlation with histopathologic findings. $\mathrm{J}$ Nucl Med. 2006;47(6):938-944.

29. Reske SN, Blumstein NM, Glatting G. [11C]choline PET/CT imaging in occult local relapse of prostate cancer alter radical prostatectomy. Eur J Nucl Med Mol Imaging. 2007; acceso electrónico: DOI 10.1007/s00259-007-0530-2.

30. Fanti S, Nanni C, Ambrosini V, Gross MD, Rubello D, Farsad M. PET in genitourinary tract cancers. $\mathrm{Q} \mathrm{J}$ Nucl Med Mol Imaging. 2007;51(3):260-271.

31. Bouchelouche K, Oehr P. Recent developments in urologic oncology: positron emission tomography molecular imaging. Curr Opin Oncol 2008;20(3):321-326.

32. Hofer C, Laubenbacher C, Block T, Breul J, Hartung R, Schwaiger M. Fluorine-18-fluorodeoxyglucose positron emission tomography is useless for the detection of local recurrence after radical prostatectomy. Eur Urol. 1999;36(1):31-35.

33. Effert PJ, Bares R, Handt S, Wolf JM, Bull U, Jakse G. Metabolic imaging of untreated prostate cancer by positron emission tomography with 18-fluorine-labeled deoxyglucose. J Urol. 1996; 155:994-998.

34. Dimitrakopoulou-Strauss A, Strauss LG. PET imaging of prostate cancer with 11C-acetate. J Nucl Med. 2003; 44:556-8.

35. Shreve PD, Grossman HB, Gross MD, Wahl RL. Metastatic prostate cancer: initial findings of PET with 2-deoxy-2-(F-18)fluoro-D-glucose. Radiology. 1996; 199:751-6.

36. Nanni C, Castellucci P, Farsad M, Rubello D, Fanti S. 11C/18F-choline PET or $11 \mathrm{C} / 8 \mathrm{~F}$-acetate PET in prostate cancer: may a choice be recommended? Eur J Nucl Med Mol Imaging. 2007; 34:1704-5.

37. Cimitran M; Bortolus R, Morassut S, Canzonieri V, Garbeglio A, Baresic T, et al. [18F]fluorocholine PET/CT imaging for the detection of recurrent prostate cancer at PSA relapse: experience in 100 consecutive patients. Eur J Nucl Med Mol Imaging. 2006;33:1387-1398.

38. Morris MJ, Scher HI. 11C-acetate PET imaging in prostate cancer. Eur J Nucl Med Mol Imaging. 2007;34(2):181-184.

39. Kotzerke J, Volkmer BG, Glatting G, van den Hoff. J, Gschwend JE, Messer $\mathrm{P}$, et al. Intraindividual comparison of [11C]acetate and [11C]choline PET for detection of metastases of prostate cancer. Nuklearmedizin. 2003; 42:25-30.

40. Picchio M, Messa C, Landoni C, Gianolli L, Sironi S, Brioschi M, et al. Value of [11C]choline-positron emission tomography for restaging prostate cancer: a comparison with [18F]fluorodeoxyglucose-positron emission tomography. J Urol. 2003;169 (4):1337-1340.

Correspondencia autor: Dr. Roberto C. Delgado Bolton

Servicio de Medicina Nuclear. Hospital Clínico Univ. San Carlos

Profesor Martín Lagos, s/n - 28040 Madrid. Tel. 913303415

E-mail autor: rbolton@telefonica.net

Información artículo: Original - Revisión de conjunto

Trabajo recibido: septiembre 2008

Trabajo aceptado: octubre 2008 